\title{
НАЛОГООБЛОЖЕНИЕ ОРГАНИЗАЦИЙ
}

\author{
Оробинская И.В., Оробинский А.С., Осипенко И.В.
}

\section{ЗНАЧЕНИЕ НААОГА НА ПРИБЫАЬ ОРГАНИЗАЦИЙ В АОХОАНОЙ ЧАСТИ КОНСОАИАИРОВАННОГО БЮАЖЕТА РОССИИ}

\begin{abstract}
Аннотащия. Предметом исследования являются экономические отночения, возникающие в процессе налогообложения между государством с одной стороны и организацией, как субъекта налогообложения с другой стороны. Объектом исследования является налог на прибыль организаций и его доля в доходной части консолидированного бюджета Российской Феде рации. Проведенные в работе исследования показали, что в налоговых доходах бюджета Российской Федерации основную долю составляют такие налоги, как НАС и налог на прибыль организаиий, что свидетельствует о фискальном значении этих платежей. Методологической основой исследования послужили фундаментальные концепции, представленные в трудах отечественных и зарубежных ученых, законодательные и нормативно-правовые акты государственных органов власти, федеральные законы, Указы Президента и Постановления Правительства РФ, материалы научно-практических конференций, затрагивающие вопросы налогообложения.В работе использованы абстрактно-логический, монографический, статистико-экономический и другие методы экономических исследований. На основе проведенного анализа, делается вывод о том, что планирование консолидированного бюджета Российской Федерации представияется весьма важной деятельностью, в сиуу того, что денежные средства, которыми управляет государство в настоящее время, могут достаточно сильно отличаться от планируемой суммы, а как следствие - возникновение профицита или дефицита бюджета.
\end{abstract}

Ключевые слова: Консолидированный бюджет, ВВП, налоговые доходы, налог на прибыль, НАС, дефичит, профицит, налоговая задолженность, ЦЧР, Воронежскал область.

Abstract. The subject of the research is the economic relations arising in the process of taxation between the state, on the one hand, and an organisation as a subejct of taxation, on the other hand. The object of the 
research is the organisatino profits tax and its share in the revenue side of the consolidated budget of the Russian Federation. The results of the research demonstrate that the Russian Federation budget revenues are mainly composed of such taxes as VAT and organisation profits tax which proves the fiscal importance of these payments. The methodological basis of the research includes fundamental concepts presented by Russian and foreign researchers, legislative and regulatory actsof state authorities, federal laws, Decrees of the President and Russian Federation Government Regulations as well as materials of research-and-science conferences on the matters of taxation. In their research the authors have used the abstract-logical, monographic, statisticaleconomical and other methods of economic research. Based on the results of the analysis, the authors conclude that the funds currently managable by the government might greatly differ from the target amount which may lead to the budget surplus and deficit.

Key words: Voronezh Oblast, Central Black Earth Economic Region, tax payable, surplus, deficit, VAT, profit tax, tax revenues, GDP, consolidated budget.

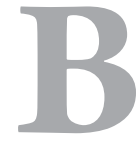
настоящее время бюАжетный кодекс подробно характеризует доходы бюАжетов на разных уровнях по виАам и по каЖАОмУ УРовню бюАЖетной системы в отАельности. СлеАует отметить, что доходы и расходы бюАжета преАставляют собой экономические формы последовательного распределения и перераспределения части валового внутреннего продукта, сосредоточенного в руках государства. Это объективно обусловленные экономические категории, гАе у каждой есть свое специфическое значение: доходы выступают в роли финансовой базы в процессе Аеятельности соответствующего органа государственной власти, а расходы в свою очереАь УАовлетворяют общественные потребности.

Мы считаем, что федеральный бюАжет - это наиболее важный эмемент бюАжетной системы РФ. В масштабах государства в целом по экономике он явцяется киючевым инструментом перераспределения ВВП национального дохода. Именно на этом уровне бюджетной системы сформировываются важнейшие направления бюАжетной политики, определение основополагающих принципов межбюАжетных отношений и приемлемых бюАжетных приоритетов. АохоАы же консолидированного бюджета состоят из среАств по взаимным расчетам, налоговых и неналоговых поступлений.

На рисунке 1 отражена структура доходной части консолидированного бюАжета Российской Федерации.

Аанные бюАжетной статистики свидетельствуют о том, что основная часть поступлений в консолидированный бюджет РФ формируется за счет налоговых платежей. Так, на их Аолю прихоАится более $80 \%$ всех поступлений.

Таблица 1.

\section{Анализ поступления налоговьх доходов в бюджеты различных уровней РФ виелом по экономике за 2011-2014 г2. (млрд. руб.)}

\begin{tabular}{|l|c|c|c|c|}
\hline \multicolumn{1}{|c|}{ Виды бюАжетов } & $\mathbf{2 0 1 1}$ г. & $\mathbf{2 0 1 2}$ г. & $\mathbf{2 0 1 3}$ г. & $\mathbf{2 0 1 4}$ г. \\
\hline Федеральный бюАжет РФ & 4477 & 5162 & 4840 & 6152 \\
\hline $\begin{array}{l}\text { Консолидированный } \\
\text { бюджет субъекта: }\end{array}$ & 5237 & 5791 & 5365 & 6453 \\
\hline $\begin{array}{l}\text { из него в доходы местных } \\
\text { бюджетов }\end{array}$ & 853 & 933 & 921 & 943 \\
\hline $\begin{array}{l}\text { Итого налоговых } \\
\text { поступлений }\end{array}$ & 9714 & 10953 & 10205 & 12605 \\
\hline
\end{tabular}

При рассмотрении Аанных приведенных в таблице 1 можно сделать вывоА, о том, что в период с 2011 года по 2014 год аоходы федерального бюАжета РФ увеличились на 1675 млрА. рублей. Аоходы же консолидированного бюджета субъектов РФ в периол с 2011 - 2014 гг. увеличились на 1216 млрА. рублей, из них 90 млрА. рублей составили Аоходы местных бюАжетов. УАельный вес и структура налоговых выплат в консолидированный бюАжет РФ в целом по экономике за 2011-2014 гг. преАставлена в таблице 2.

Как виАно из таблицы 2, основными источниками формирования доходов консолидированного бюджета явмяется НАФ $\Lambda$ и налог на прибыль организации. УАельный вес налоговых поступлений в консолидированный бюАжет за 2014 гоА преАставлен на рисунке 2. 


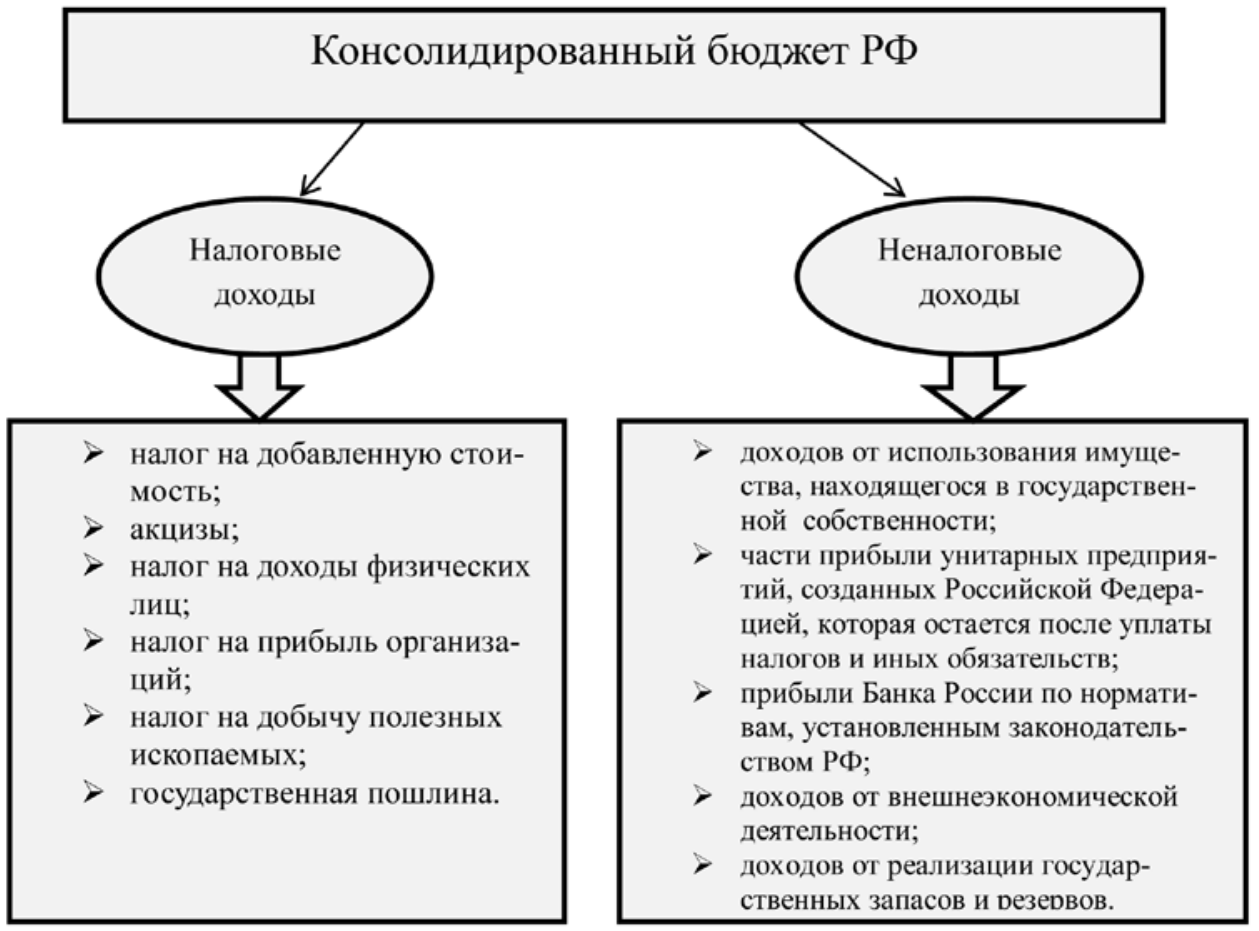

Рисунок 1. Структура доходов консолидированного бюджета РФ

Структура налоговых платежей в консолидированный бюджет РФ

Таблица 2. в целом по экономике за 2011-2014 г2., (мирд. руб.)

\begin{tabular}{|c|c|c|c|c|c|c|c|c|}
\hline \multirow{2}{*}{ Наименование показатемя } & \multicolumn{2}{|c|}{2011 г. } & \multicolumn{2}{|c|}{2012 г. } & \multicolumn{2}{|c|}{2013 г. } & \multicolumn{2}{|c|}{2014 r. } \\
\hline & мАрА. руб. & $\%$ & мАрА. руб. & $\%$ & мАрА. руб. & $\%$ & мирА. руб. & $\%$ \\
\hline Намог на прибыль организаций & 1927 & 26 & 2355 & 21 & 2071 & 18 & 2372 & 19 \\
\hline Намог на Аоходы физических миц & 1994 & 27 & 2260 & 21 & 2497 & 22 & 2688 & 21 \\
\hline $\mathrm{HAC}$ & 1962 & 26 & 1988 & 18 & 1977 & 17 & 2300 & 18 \\
\hline Акцизы & 372 & 5 & 785 & 7 & 958 & 8 & 1010 & 8 \\
\hline Намоги на имущество & 677 & 9 & 785 & 7 & 900 & 8 & 955 & 8 \\
\hline Аругие налоговые доходы & 267 & 3 & 2486 & 23 & 2587 & 23 & 2864 & 23 \\
\hline Всего налоговых поступлений & 9714 & 100 & 10953 & 100 & 10205 & 100 & 12605 & 100 \\
\hline
\end{tabular}

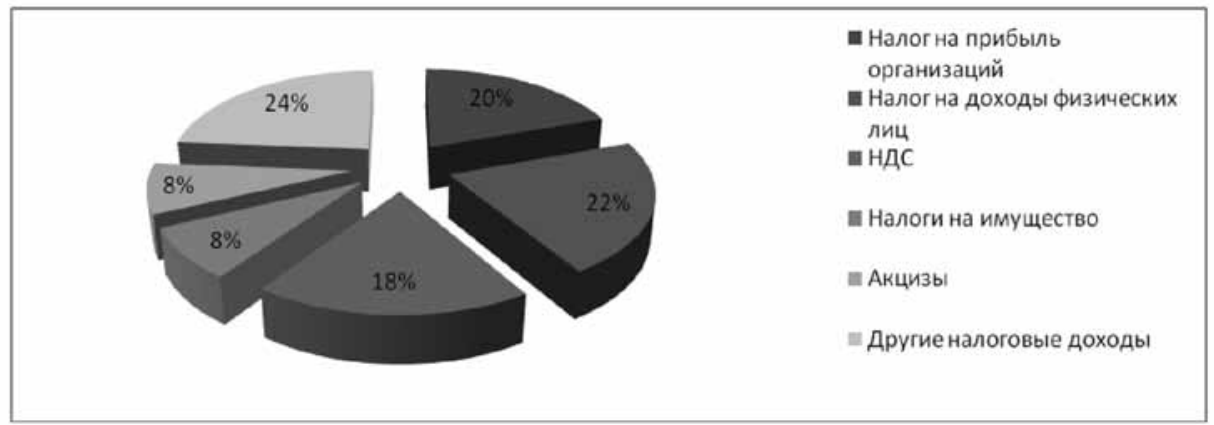

Рисунок 2. Удельный вес налоговых поступлений в консолидированный бюджет за 2014 год

При анализе уровня налоговой нагрузки в Российской Федерации налогу на прибымь отводится основном место по реализации стабильного, крУпного и оАного из основных АОходОв бюАжета. Амя большей нагмяАности рассмотрим Аинамику изменений намога на прибыль органи- заций за последние 3 года и плановый период на 2016-2017 годов.

В связи с тем, что начисленные суммы дохоАов с кажАЫм Годом увеличиваются, повышается и сумма задолженности переА бюАжетами размичных уровней. В таблице 3 преАставлена за- 


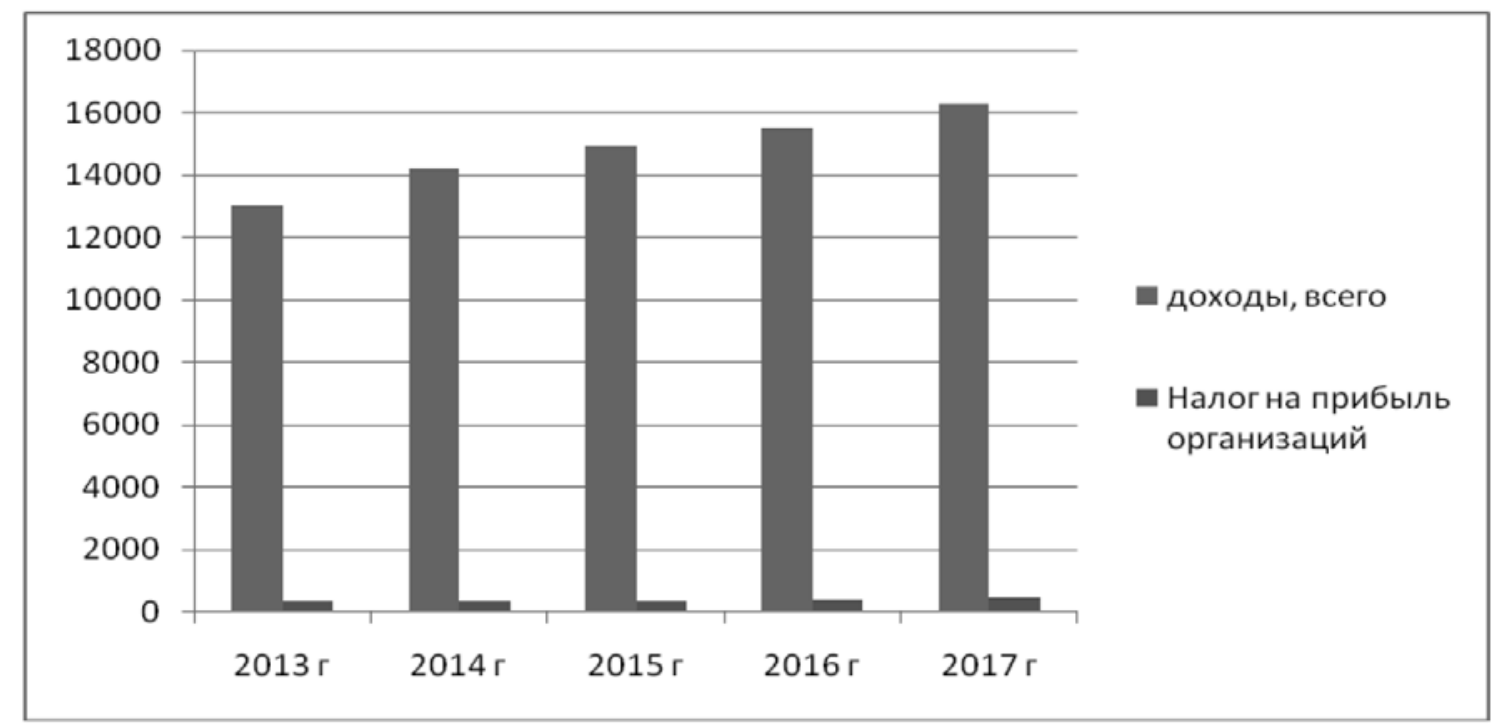

Рисунок 3. Динамика изменений налога на прибыль за 2013-2017 г2.

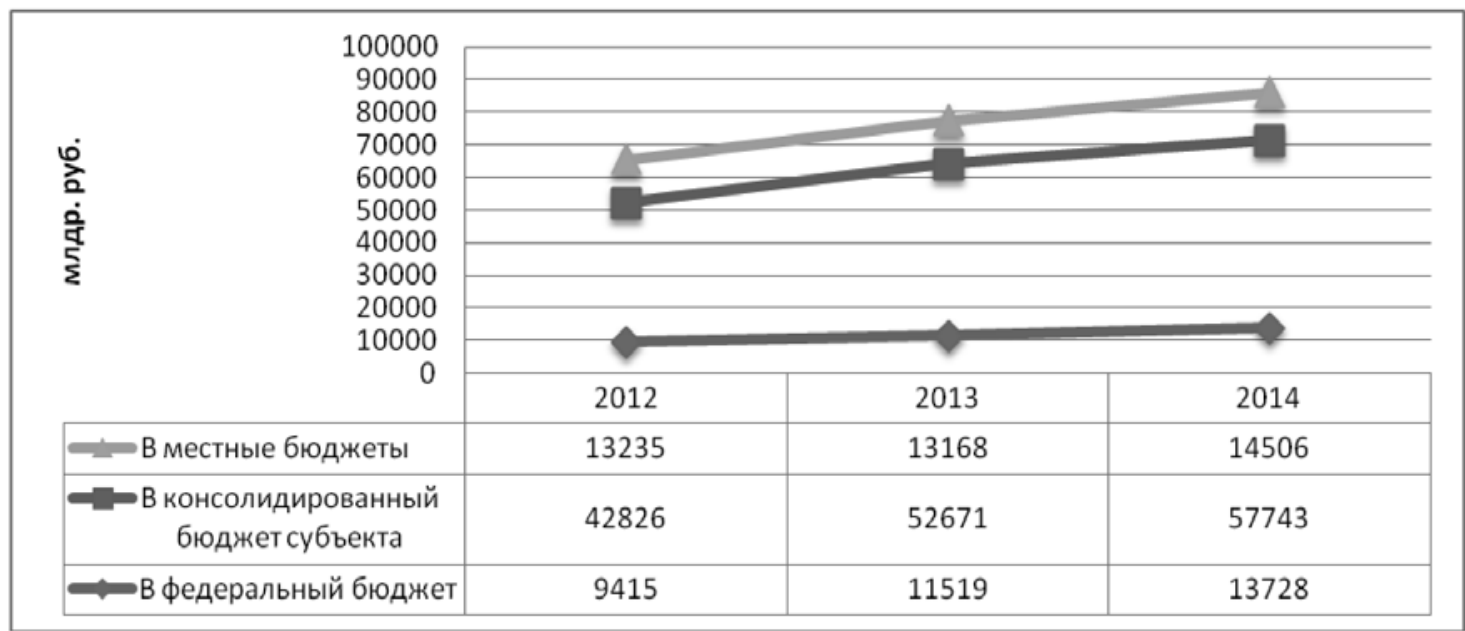

Рисунок 4. Налоговые поступления в бюджеты различных уровней по Воронежской области за 2011-2013 гг. (млрд. руб.)

Аолженность в бюАжеты разАичных уровней по налогам и сборам. Так, в период с 2011 - 2014 гг. задомженность по налогу на прибыць организации увеличилась на 21 млрА. рублей.

На наш взгляА Аля бомее гмубокого изучения фискального значение налога на прибыль организаций в Аоходной части консолиАированного бюджета Российской Федерации целесообразно его рассмотреть на уровне субъектов, так бомьшая его часть (18\%) зачисляется в региональные бюАжеты.

Рассмотрим структуру поступления намогов по областям Центрально-черноземного района (таблица 4).

Так из приведенной выше таблицы видно, что среАи областей ЦЧР Воронежская область занимает первое место по векичине собираемых налогов и за 2014 гоА в бюАжет Воронежской области поступимо 67 ммрА руб. налоговых платежей. Наибольшая величина налоговых дохоАОв по ЦЧР в 2014 году была обеспечена за счет НАФА и налог на прибыль организаций. Поступления от специальных налоговых режимов в Воронежской области составимо 3,86 мирА. руб., в Тамбовской - 1,37ммрА. руб., в Курской $-1,77$ ммрА. руб. (таблица 6).

Налоговые поступления в бюАжеты размичных уровней по Воронежской области преАставмены на рисунке 4.

Анализируя данные приведенные на рисунке 2, можно саелать вывоА о том, что за периоА с 2012 года по 2014 год поступления в бюАжеты 
Таблица 3.

Задолженность в бюджеты различных уровней по налогам и сборам в РФ в 201 1-2014 г2., млрд. руб.

\begin{tabular}{|c|c|c|c|c|}
\hline Задолженность & 2011 г. & 2012 г. & 2013 г. & 2014 г. \\
\hline Общая сумма задолженности & 672 & 725 & 767 & 802 \\
\hline \multicolumn{5}{|l|}{ в том числе: } \\
\hline По налогу на прибымь организаций & 160 & 175 & 165 & 137 \\
\hline По налогу на Аобавленную стоимость & 305 & 319 & 333 & 368 \\
\hline По платежам за пользование природными ресурсами & 5 & 4 & 4 & 4 \\
\hline По остальным федеральным налогам и сборам & 82 & 92 & 106 & 104 \\
\hline По региональным налогам и сборам & 77 & 83 & 96 & 133 \\
\hline По местным намогам и сборам & 26 & 32 & 39 & 49 \\
\hline По налогам со специальным налоговым режимом & 17 & 20 & 24 & 25 \\
\hline
\end{tabular}

Таблица 4.

Величина налоговых доходов в консолидированном бюджете областей ЦЧР в 2014 г., млрд руб.

\begin{tabular}{|l|c|c|c|}
\hline \multicolumn{1}{|c|}{ Намоги } & Курская обмасть & Воронежская область & Тамбовская обмасть \\
\hline Намог на прибымь организаций & 11,54 & 14,49 & 3,38 \\
\hline Намог на Аоходы физических миц & 11,39 & 24,89 & 8,69 \\
\hline Намог на Аобавменную стоимость & 6,38 & 11,78 & 1,44 \\
\hline Акцизы & 0,46 & 2,90 & 0,20 \\
\hline Намог на имущество организаций & 2,80 & 6,43 & 1,88 \\
\hline Прочие намоги и сборы & 3,50 & 6,50 & 2,73 \\
\hline Всего намоговых поступлений & 36,07 & 66,99 & 18,32 \\
\hline
\end{tabular}

Таблица 5.

Удельный вес и структура налоговьх платежей

в консолидированный бюджет РФ по Воронежской области за 201 1-2014 г2.

\begin{tabular}{|c|c|c|c|c|c|c|c|c|}
\hline \multirow{2}{*}{ Наименование показатемя } & \multicolumn{2}{|c|}{2011 г. } & \multicolumn{2}{|c|}{2012 r. } & \multicolumn{2}{|c|}{2013 г. } & \multicolumn{2}{|c|}{2014 г. } \\
\hline & ммра. руб. & $\%$ & ммрА. руб. & $\%$ & ммрА. руб. & $\%$ & ммра. руб. & $\%$ \\
\hline Налог на прибыль организаций & 13061 & 24,9 & 15716 & 24,5 & 15406 & 21,5 & 15056 & 19,7 \\
\hline $\mathrm{H} A \Phi \Lambda$ & 19146 & 36,5 & 22333 & 34,8 & 24895 & 34,7 & 27155 & 35,6 \\
\hline $\mathrm{HAC}$ & 9514 & 18,2 & 12135 & 18,9 & 15596 & 21,8 & 17054 & 22,3 \\
\hline Намоги на имущество & 7463 & 14,2 & 9765 & 15,2 & 11214 & 15,6 & 11883 & 15,6 \\
\hline Транспортный намог & 1510 & 2,9 & 1687 & 2,6 & 1966 & 2,7 & 2135 & 2,8 \\
\hline Земельный налог & 1630 & 3,1 & 2244 & 3,5 & 2507 & 3,5 & 2937 & 3,8 \\
\hline Аругие налоговые поступмения & 82 & 0,2 & 310 & 0,5 & 113 & 0,2 & 104 & 0,1 \\
\hline Всего налогов и сборов & 52406 & 100 & 64190 & 100 & 71697 & 100 & 76324 & 100 \\
\hline
\end{tabular}

Таблица 6.

Структуру налоговьх платежей по налогу на прибыль организаций в Воронежской области за 2011-2014 г2. (млрд. руб.)

\begin{tabular}{|c|c|c|c|c|c|c|c|c|}
\hline \multirow{2}{*}{ Наименование показатемя } & \multicolumn{2}{|c|}{2011 г. } & \multicolumn{2}{|c|}{2012 r. } & \multicolumn{2}{|c|}{2013 г. } & \multicolumn{2}{|c|}{2014 r. } \\
\hline & ммрА. руб. & $\%$ & ммра. руб. & $\%$ & ммрА. руб. & $\%$ & ммрА. руб. & $\%$ \\
\hline в федеральный бюАжет & 1812 & 14 & 1032 & 7 & 915 & 6 & 970 & 6 \\
\hline в консолидированный бюджет субъекта РФ & 11249 & 86 & 14684 & 93 & 14491 & 94 & 14186 & 94 \\
\hline из него - в Аоходы местных бюАжетов & 562 & 4 & 0 & 0 & 0 & 0 & 0 & 0 \\
\hline Всего поступлений по налогу на прибыль & 13061 & 100 & 15716 & 100 & 15406 & 100 & 15156 & 100 \\
\hline
\end{tabular}

всех уровней в разрезе субъектов РФ (Воронежской области) увекичились.

На основании данных приведенных в таблице 5, можно сделать вывоА о том, что наибольший УАельный вес в структуре налоговых платежей составляет НАФ $\Lambda$ и налог на прибыль организации.

Величину и распределение налога на прибыль организаций в Воронежской области преАставлена в таблице 6.
Проведенный анализ позволил определить место, которое занимает исследуемый налог в Аоходной части РФ. Нами были проанализированы налоговые поступления бюАжетов всех уровней, и их распределение, а кроме того задолженность переА бюАжетом. Основываясь на Аанных проведенного исследования, следует сАелать вывоА о том, что планирование консолидированного бюджета Российской Федерации явмяется весьма не простой и важной деятельность государства. 


\section{ФИНАНСОВОЕ ПРАВО И УПРАВАЕНИЕ • $2 \cdot 2016$}

\section{БИБАИОГРАФИЯ}

1. Брянцева, А.В. Сущность налогового мониторинга как нового вида налогового аАминистрирования / А.В. Брянцева, И.В. Оробинская, И.Н. Маслова / / Вестник Воронежского государственного аграрного университета. - 2014.-№ 4 (43). - С. 189-199.

2. Казьмин, А.Г. Таможенное регулирование в России после присоеди-нения к ВТО / А.Г. Казьмин, И.В. Оробинская / / Финансы и креАит. - 2013. - № 48 (576).-С. 46-55

3. Камалян А.К. Страхование как инструмент государственного регулирования в сельскомхозяйстве / А.К. Камамян, И.В. Оробинская, А.С. Оробинский, Ю.Н. Парахин / Под реАакцией профессора Камамяна А.К.-. Воронеж,-2010.

4. Налоговый кодекс Российской Федерации (часть вторая) от 31.07.1998 № 146-Ф3 (реА. от 04.08.2015) [Электронный ресурс] - Справочно-правовая система Консультант Пцюс. - М.: ЗАО «Консультант Плюс». - Режим доступа: http://www.consultant.ru

5. Оробинская И.В.Изменение внешней и внутренней политики Российской ФеАерации в отношении сельхозтоваропроизводителей в условиях вступления в ВТО / И.В. Оробинская, А.В. Бурыка // Намоги и нахогообложение.-2012.-№ 9-10.-С. 30-33

6. Оробинская, И.В. Налоговые инструменты обеспечения стабильного развития отраслей АПК / И.В. Оробинская / / Намоги и налогообложение. - 2014. - № 4. - С.501-508

7. Оробинская, И.В.Характеристика намогового потенциала субъектов аграрного сектора России на примере областей ЦЧР/ И.В. Оробинская // Налоги и налогообложение. - 2014. - № 6. C. 579-587.

8. Основные направления налоговой политики Российской Федерации на 2015 гоА и на плановый период 2016 и 2017 годов //http://vestnikao.ru

9. Основные направления налоговой политики Российской Федерации на 2015 гоА и на плановый период 2016 и 2017 годов // http:/ / garant.ru

10. Проблемы налогового законодательства РФ: налог на Аобавленную стоимость, налог на прибыль, регистрация налогопмательщиков: Моногр. / Б.А.Романов-М.: ИЦ РИОР:НИЦ Инфра-М,-2012-174с

11. Проект Основные направления налоговой политики Российской Фе-Аерации на 2015 гоА и на плановый период 2016 и 2017 годов: Эмектронный ресурс: режим доступа: http: / www.eg-online.ru

12. Оробинская И.В. Характеристика налогового потенциала субъектов аграрного сектора России на примере областей ЦЧР // Налоги и налогообложение. - 2014. - 6. - С. 579 - 587. DOI: 10.7256/1812-8688.2014.6.11783.

13. Кондрашова Н.А. Налог на прибыль консолиАированной группы налогопмательщиков // Налоги и налогообложение. - 2015. - 6. - С. 439 - 447. DOI: 10.7256/1812-8688.2015.6.13585.

14. Байков П.М., Королева А.П.Налоговые Аоходы бюАжетов городских округов - столиц финно-угорских автономий Приволжского федерального округа РФ: анализ и преАложения по расширению // Налоги и налогообложение. - 2014. - 6. - С. 604 - 613. DOI: 10.7256/1812-8688.2014.6.12200.

15. А.Г. Казьмин, И.В. Оробинская Оценка современного состояния системы налогообложения Воронежской области // Налоги и налогообложение. - 2012. - 7. - С. 17 - 27.

16. Агузарова Ф.С. Роль косвенных и прямых налогов и сборов в формировании Аоходов бюАжетов бюАжетной системы Российской Федерации // Налоги и налогообложение. - 2014. - 10. - С. 910 - 918. DOI: 10.7256/1812-8688.2014.10.13209.

17. Оробинская И.В. Налоговые инструменты обеспечения стабильного развития отраслей АПК // Намоги и намогообложение. - 2014. - 4. - С. 393 - 400. DOI: 10.7256/1812-8688.2014.4.12019.

\section{REFERENCES (TRANSLITERATED)}

1. Bryantseva, L.V. Sushchnost' nalogovogo monitoringa kak novogo vida nalogovogo administrirovaniya / L.V. Bryantseva, I.V. Orobinskaya, I.N. Maslova / / Vestnik Voronezhskogo gosudarstvennogo agrarnogo universiteta. - 2014.-№ 4 (43). - S. 189-199.

2. Kaz’min, A.G. Tamozhennoe regulirovanie v Rossii posle prisoedi-neniya k VTO / A.G. Kaz'min, I.V. Orobinskaya // Finansy i kredit. - 2013. - № 48 (576).-S. $46-55$ 


\section{НААОГООБАОЖЕНИЕ ОРГАНИЗАЦИЙ}

3. Kamalyan A.K. Strakhovanie kak instrument gosudarstvennogo regulirovaniya v sel'skom khozyaistve / A.K. Kamalyan, I.V. Orobinskaya, A.S. Orobinskii, Yu.N. Parakhin / Pod redaktsiei professora Kamalyana A.K.-. Voronezh,-2010.

4. Nalogovyi kodeks Rossiiskoi Federatsii (chast' vtoraya) ot 31.07.1998 № 146-FZ (red. ot 04.08.2015) [Elektronnyi resurs] - Spravochno-pravovaya sistema Konsul'tant Plyus. - M.: ZAO «Konsul'tant Plyus». - Rezhim dostupa: http://www.consultant.ru

5. Orobinskaya I.V.Izmenenie vneshnei i vnutrennei politiki Rossiiskoi Federatsii $\mathrm{v}$ otnoshenii sel'khoztovaroproizvoditelei v usloviyakh vstupleniya v VTO / I.V. Orobinskaya, A.V. Buryka // Nalogi i nalogooblozhenie.-2012.-№ 9-10.-S. 30-33

6. Orobinskaya, I.V. Nalogovye instrumenty obespecheniya stabil'nogo razvitiya otraslei APK / I.V. Orobinskaya // Nalogi i nalogooblozhenie. - 2014. - № 4. - S.501-508

7. Orobinskaya, I.V.Kharakteristika nalogovogo potentsiala sub"ektov agrarnogo sektora Rossii na primere oblastei TsChR/ I.V. Orobinskaya // Nalogi i nalogooblozhenie. - 2014. - № 6. - S. 579-587.

8. Osnovnye napravleniya nalogovoi politiki Rossiiskoi Federatsii na 2015 god i na planovyi period $2016 \mathrm{i}$ 2017 godov //http://vestnikao.ru

9. Osnovnye napravleniya nalogovoi politiki Rossiiskoi Federatsii na 2015 god i na planovyi period $2016 \mathrm{i}$ 2017 godov // http://garant.ru

10. Problemy nalogovogo zakonodatel'stva RF: nalog na dobavlennuyu stoimost', nalog na pribyl', registratsiya nalogoplatel'shchikov: Monogr. / B.A.Romanov-M.: ITs RIOR:NITs Infra-M,-2012-174s

11. Proekt Osnovnye napravleniya nalogovoi politiki Rossiiskoi Fe-deratsii na 2015 god i na planovyi period 2016 i 2017 godov: Elektronnyi resurs: rezhim dostupa: http://www.eg-online.ru

12. Orobinskaya I.V. Kharakteristika nalogovogo potentsiala sub"ektov agrarnogo sektora Rossii na primere oblastei TsChR // Nalogi i nalogooblozhenie. - 2014. - 6. - C. 579 - 587. DOI: 10.7256/1812-8688.2014.6.11783.

13. Kondrashova N.A. Nalog na pribyl' konsolidirovannoi gruppy nalogoplatel'shchikov // Nalogi i nalogooblozhenie. - 2015. - 6. - C. 439 - 447. DOI: 10.7256/1812-8688.2015.6.13585.

14. Baikov P.M., Koroleva L.P. Nalogovye dokhody byudzhetov gorodskikh okrugov - stolits finnougorskikh avtonomii Privolzhskogo federal'nogo okruga RF: analiz i predlozheniya po rasshireniyu // Nalogi i nalogooblozhenie. - 2014. - 6. - C. 604 - 613. DOI: 10.7256/1812-8688.2014.6.12200.

15. A.G. Kaz'min, I.V. Orobinskaya Otsenka sovremennogo sostoyaniya sistemy nalogooblozheniya Voronezhskoi oblasti // Nalogi i nalogooblozhenie. - 2012. - 7. - C. 17 - 27.

16. Aguzarova F.S. Rol' kosvennykh i pryamykh nalogov i sborov $\mathrm{v}$ formirovanii dokhodov byudzhetov byudzhetnoi sistemy Rossiiskoi Federatsii // Nalogi i nalogooblozhenie. - 2014. - 10. - C. 910 - 918. DOI: $10.7256 / 1812-8688.2014 .10 .13209$.

17. Orobinskaya I.V. Nalogovye instrumenty obespecheniya stabil'nogo razvitiya otraslei APK // Nalogi i nalogooblozhenie. - 2014. - 4. - C. 393 - 400. DOI: 10.7256/1812-8688.2014.4.12019. 